\title{
Spatial Differentiation Analysis of Water Quality in Dianchi Lake Based on GF-5 NDVI Characteristic Optimization
}

\author{
Hu Lin $\mathbb{D}^{1},{ }^{1}$ Gan Shu $\mathbb{D}^{1,2}$ Yuan Xiping, ${ }^{2,3}$ Li Yan, ${ }^{1}$ Chen Guokun, ${ }^{1}$ and Gao Sha ${ }^{1}$ \\ ${ }^{1}$ School of Land and Resources Engineering, Kunming University of Science and Technology, Kunming 650093, China \\ ${ }^{2}$ Application Engineering Research Center of Spatial Information Surveying and Mapping Technology in \\ Plateau and Mountainous Areas Set by Universities in Yunnan Province, Kunming 650093, China \\ ${ }^{3}$ West Yunnan University of Applied Sciences, Dali 671006, China \\ Correspondence should be addressed to Gan Shu; gs@kust.edu.cn
}

Received 20 January 2021; Revised 18 July 2021; Accepted 17 August 2021; Published 26 August 2021

Academic Editor: Khalique Ahmed

Copyright $\odot 2021 \mathrm{Hu}$ Lin et al. This is an open access article distributed under the Creative Commons Attribution License, which permits unrestricted use, distribution, and reproduction in any medium, provided the original work is properly cited.

\begin{abstract}
Remote sensing monitoring of aquatic vegetation is critical to the water quality evaluation of plateau lakes. To obtain a clear understanding of the water environment status of Dianchi Lake, a GF-5 hyperspectral characteristics-based optimal NDVI approach was employed to quantify the aquatic vegetation cover and analyze water quality. By characteristic bands recognition, the optimal NDVI was obtained; the spatial distribution of aquatic plants and water quality in Dianchi Lake were then analyzed. Results showed the following: (1) For Caohai, the optimal NDVI value was calculated by B86 in the red band range and B151 in the near-infrared band range, which achieve the best spectral response. For Waihai, the respective bands were B86 in the red band range and B99 in the near-infrared band range. (2) We also found significant regional differences in aquatic plants distribution for the study area. Caohai was dominated by aquatic plants and high-quality water areas only occurred in the northern tip. While the situation for Waihai was much optimistic, areas with poor water quality were mainly found in the north and south parts. Water quality also showed a descending trend from the lakeside zone to the lake center. (3) By comparing to previous studies, we concluded that policy interventions and water protection measures carried out by the government during the past years are extremely effective. The optimal NDVI method provides a reliable evaluation and is potentially transferable to other plateau lake areas as a robust approach for the rapid assessment of water quality.
\end{abstract}

\section{Introduction}

Eutrophication causes abnormal proliferation of cyanobacteria, which leads to water blooms and further destroys the ecosystem of lake water and seriously affects human health and socioeconomic development [1]. As primary producers in aquatic ecosystems and the main contributors to photosynthesis, aquatic plants maintain the energy input of ecosystems and play a significant role in ecosystems. Environmental changes produce pressure on aquatic plants, leading to changes in aquatic plants and ecosystem service functions [2]. In recent years, remote sensing monitoring approaches incorporating the growth of aquatic plants into decision making associated with water quality evaluation, water ecological environment and environmental effects of aquatic plants have been increasingly recognized by scientists and policymakers worldwide [3].
Dianchi Lake is one of the 9 lakes in Yunnan-Guizhou Plateau where aquatic plants (e.g., cyanobacteria bloom, etc.) are most likely to occur leading to poor water quality [4]. According to the data query, the water environment condition of Dianchi Lake has deteriorated sharply in the past 30 years, decreasing by 3 grades. The water quality of Dianchi Lake was classified as class II in the 1960s and class III in the 1970s. In the 1980s, the water quality of Caohai was classified as class $\mathrm{V}$ and that of Waihai was classified as class IV. And in the 1990s, it was considered inferior to that of the past; the water environment situation of Caohai was classified as superclass $\mathrm{V}$ and that of Waihai was class V [5]. Therefore, the water environment situation control of Dianchi Lake has been widely concerned by many scholars and government agencies. In recent years, through the implementation of a series of governance works in Dianchi Lake, the water 
environment of Caohai and Waihai has been improved. In 2019, Caohai accords with the class IV standard and Waihai accords with the class $\mathrm{V}$ standard, but there still exists serious contamination. Therefore, it is particularly important to strengthen the research on the water quality in Dianchi Lake based on the characteristics of ecological environmental heteroplasmy.

Compared with the traditional field water environment situation survey method, remote sensing, as a regional monitoring method, can quickly obtain the temporal and spatial distribution of aquatic plants [6], so it is more and more applied on the monitoring and management of water quality. However, due to the relatively complicated optical properties of inland lakes, small spatial scale, changeable water environment, and large spatial difference [7], multispectral remote sensing data have insufficient information and cannot meet the accuracy requirements of water quality monitoring. By contrast, hyperspectral data can better obtain the spectral characteristics of the water body and the spatial distribution difference of water quality [8], thus providing an important scientific theoretical basis and support for water quality monitoring at the regional scale.

The monitoring of aquatic plants by remote sensing technology has received widespread attention. At present, there are many satellite data available for aquatic plant research. For example, the most commonly known and easily accessible one is the Landsat satellite data of the United States. However, its disadvantages are its long revisit period and low spectral resolution [9]. Another data is MODIS satellite data with a low spatial resolution [10]. The other data is the data of China's Zhuhai-1 satellite, which has the advantage of high spatial and temporal resolution, but the disadvantage is that the acquired images only have 32 bands and spectral resolution is relatively low [5]. Compared with these data sources, China's GaoFen-5 (GF-5) satellite is known for hyperspectral imaging, short revisit period, and high spatial resolution, which provides a new remote sensing data source for the monitoring of lake water ecological environment in a large area.

Based on spectral characteristics, it can be found that the most obvious characteristic of aquatic plants is the steep slope effect in the near-infrared band, and the steep slope effect of aquatic plants with higher enrichment is more obvious [11]. Many remote sensing index methods have been proposed by scholars around the world, including Normalized Difference Vegetation Index (NDVI) [12-14], Floating Algae Index (FAI) [15, 16], Normalized Difference Water Index (NDWI) $[17,18]$, Enhanced Vegetation Index (EVI) [19], and Normalized Difference Index of Cyanobacteria Bloom (NDICB) [20]. Among them, NDVI is the most widely used remote sensing index method. It is defined as the normalized ratio of red and near-infrared bands, which can better reflect the steep slope effect and improve the monitoring efficiency. Therefore, NDVI is selected as the basic index for aquatic plant monitoring in this study. However, when calculating NDVI with hyperspectral data, how to filter bands to achieve the effective construction of NDVI has become our challenge. Hence, this study aims to acquire the hyperspectral characteristics of Dianchi Lake water based on GF-5 hyperspectral remote sensing images and provide a theoretical basis for the optimization of NDVI construction. Then, the spatial distribution of aquatic plants in Dianchi Lake was obtained according to the optimized NDVI, as well as spatial differentiation of the water quality in Dianchi Lake. Comparing to NDVI calculated by the conventional methods, NDVI based on the optimized construction can better reflect the growth and distribution of aquatic plants. And this method can be effectively applied to the monitoring of lake water quality, providing a reference for the scientific management of water resources in the plateau region.

\section{Materials and Methods}

2.1. Study Area. Dianchi Lake $\left(24^{\circ} 40^{\prime}-25^{\circ} 02^{\prime} \mathrm{N}\right.$, $102^{\circ} 36^{\prime}-102^{\circ} 47^{\prime} \mathrm{E}$ ) is located in southwestern Kunming, Yunnan Province of China (Figure 1). Due to the extreme eutrophication of the water body [12], it has received widespread attention in recent years. As the largest plateau lake in Yunnan Province and the sixth-largest freshwater lake in China, Dianchi covers a total area of $2920 \mathrm{~km}^{2}$ [21], with a north-to-south length of $40.4 \mathrm{~km}$ and a west-to-east width of $7 \mathrm{~km}$, the coastline is $163.2 \mathrm{~km}$, and the average water volume is $1.56 \times 10^{9} \mathrm{~m}^{3}$ [22]. The lake elevation is $1887.4 \mathrm{~m}$ and the lake shoreline is about $150 \mathrm{~km}$. The average water depth is $5 \mathrm{~m}$; the deepest is $8 \mathrm{~m}$. The dam located in the northern part of the lake divides the Dianchi Lake into Caohai and Waihai artificially. The north part is called Caohai, with a lake area of $10.8 \mathrm{~km}^{2}$ (at $1887.4 \mathrm{~m}$ elevation), accounting for only $3.4 \%$ of the Dianchi Lake area. The average water depth of Caohai is $2.5 \mathrm{~m}$, lush grass, natural pond [23]. The south part is known as Waihai, with an area of $298.2 \mathrm{~km}^{2}$ (at $1887.4 \mathrm{~m}$ elevation), which is the main component of Dianchi Lake, and the average depth is about $5 \mathrm{~m} \mathrm{[4].}$

2.2. Data. GF-5 AHSI hyperspectral remote sensing satellite was successfully launched on May 9, 2018, with a spatial resolution of $30 \mathrm{~m}$. The hyperspectral datasets are divided into visible light near-infrared (VNIR) subset and shortwave infrared (SWIR) subset, according to different spectral resolutions. Among them, VNIR has 150 bands and SWIR has 180 bands, with a total of 330 bands. The band range of VNIR is about $0.39-1.03 \mu \mathrm{m}$ with a resolution interval of $5 \mathrm{~nm}$, and the band range of SWIR is about $1.0-2.5 \mu \mathrm{m}$ with a resolution interval of $10 \mathrm{~nm}$ [24]. GF-5 is characterized by high spatial resolution, high temporal resolution, and high spectral resolution [25], which can better meet the experimental needs of this study. In this study, the GF-5 hyperspectral data used was obtained on December 16, 2019. The basic parameters of the GF-5 hyperspectral payload are shown in Table 1 [26]. The wavelength of the red band is $620-760 \mathrm{~nm}$, and that of the near-infrared band is 760-3000 nm [27], corresponding to GF-5 B55-87 and B88330 , respectively. To utilize the images for the subsequent experimental analysis, the GF-5 data was preprocessed first using ENVI software. The preprocessing procedure includes 

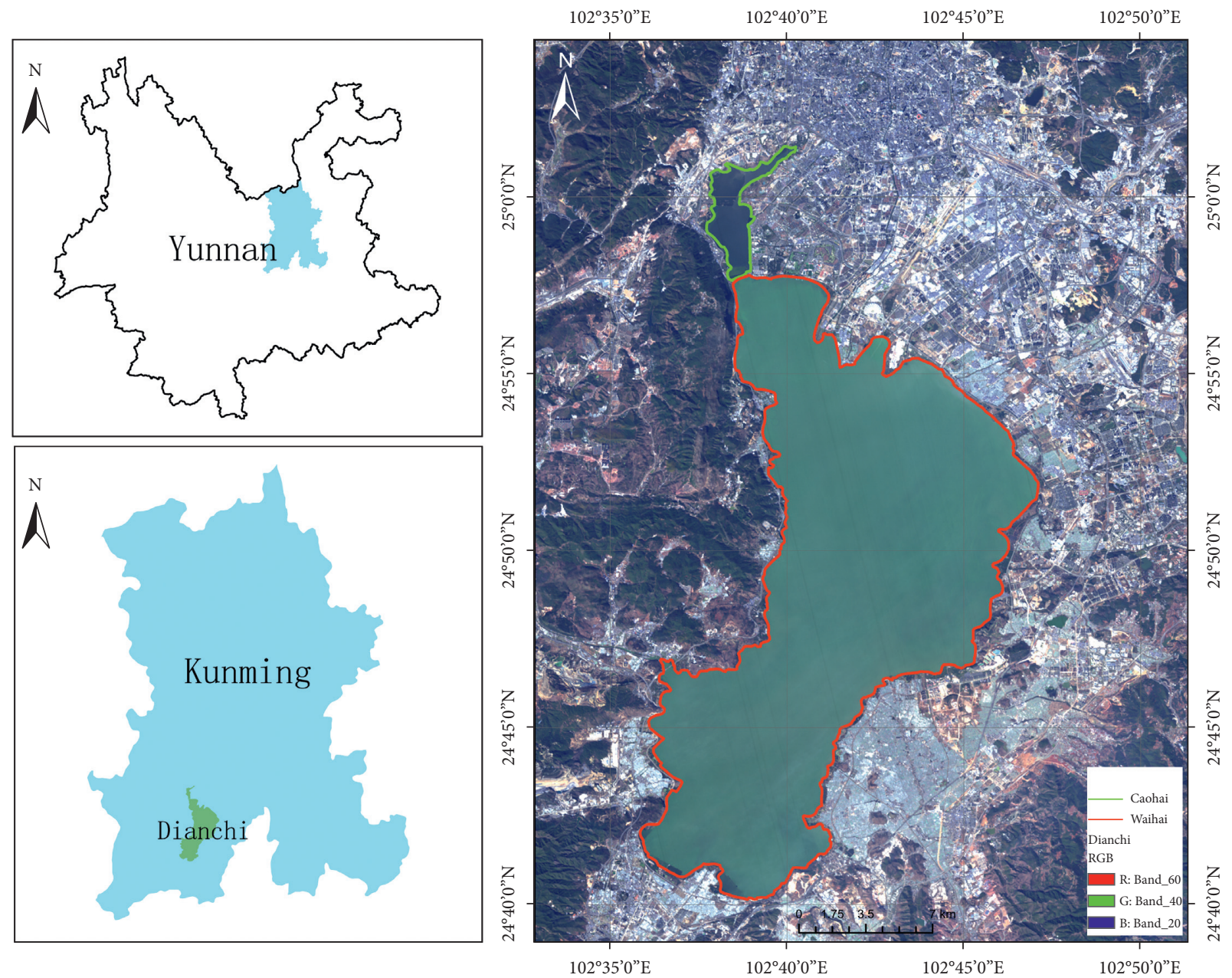

Figure 1: Location of the study area.

TABLE 1: Basic parameters of GF-5 hyperspectral payload.

Spectral range $(\mathrm{nm}) \quad$ Spatial resolution $(\mathrm{m})$ Width $(\mathrm{km}) \quad$ Spectral resolution $(\mathrm{nm}) \quad$ Number of bands Average orbital height $(\mathrm{km})$ \begin{tabular}{llllll}
\hline $400-2500$ & 30 & 60 & VNIR: 5; SWIR: 10 & 330 & 705
\end{tabular}

radiation calibration, FLAASH atmospheric correction, orthographic correction, image clipping, bad band and noise band removal. The specific preprocessing flowchart is shown in Figure 2.

2.3. Methods. To use hyperspectral technology and scientifically analyze the spatial differentiation of water quality in Dianchi Lake based on remote sensing index NDVI, the experimental scheme of this study is as follows. Firstly, we calculated the average spectral reflectance of Caohai and Waihai and the reflectance spectral curves were drawn, respectively. Since NDVI is defined as the ratio of the difference to a sum between the reflection value of the nearinfrared band and that of the red band for remote sensing images [28], namely, NDVI $=(\mathrm{NIR}-\mathrm{R}) /(\mathrm{NIR}+\mathrm{R})$. The optimal construction scheme of NDVI was then studied based on the characteristic bands of red and near-infrared bands. Finally, according to the optimized NDVI, the growth status of aquatic plants in Dianchi Lake was presented; the spatial distribution differentiation of water environment situation in Dianchi Lake was analyzed. The specific flowchart is shown in Figure 3.

\section{Results}

3.1. Characteristic Analysis of the Red Band. Spectral reflection curves of the red band for Caohai and Waihai are shown in Figure 4. As can be seen, both curves fluctuate up and down with the increase of band number. In the red band range, spectral curves show that variation trends for the two water bodies are similar, but the reflectance of Waihai is greater than that of Caohai. The maximum (max) reflectance difference is $1.42 \%$ in $\mathrm{B} 74$, and the minimum ( $\min$ ) is $0.27 \%$ in B87. Furthermore, Waihai shows a more obvious absorption peak in B61, while the curve of Caohai is relatively stable. The detailed information is shown in Table 2. 


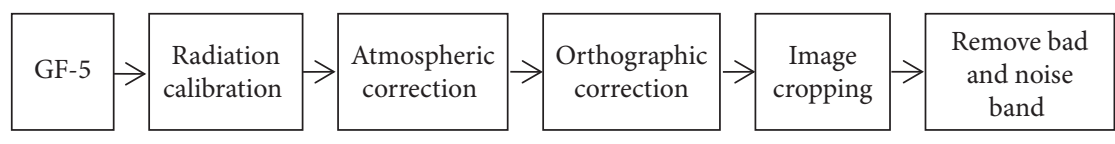

FIGURE 2: GF-5 data preprocessing flowchart.

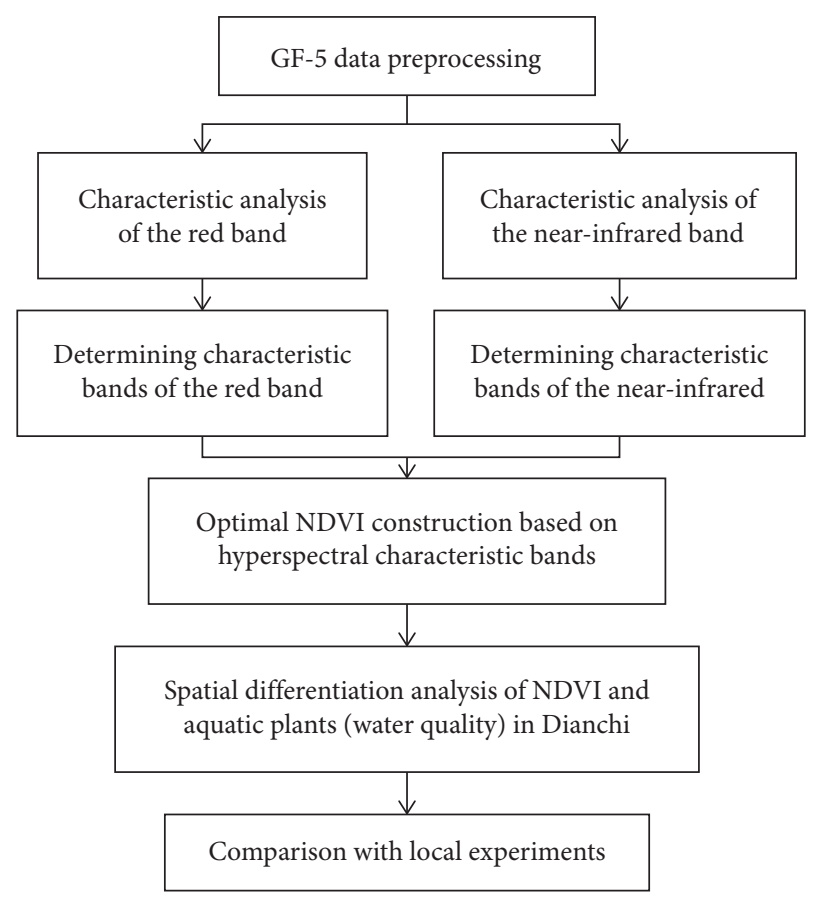

Figure 3: Flowchart.

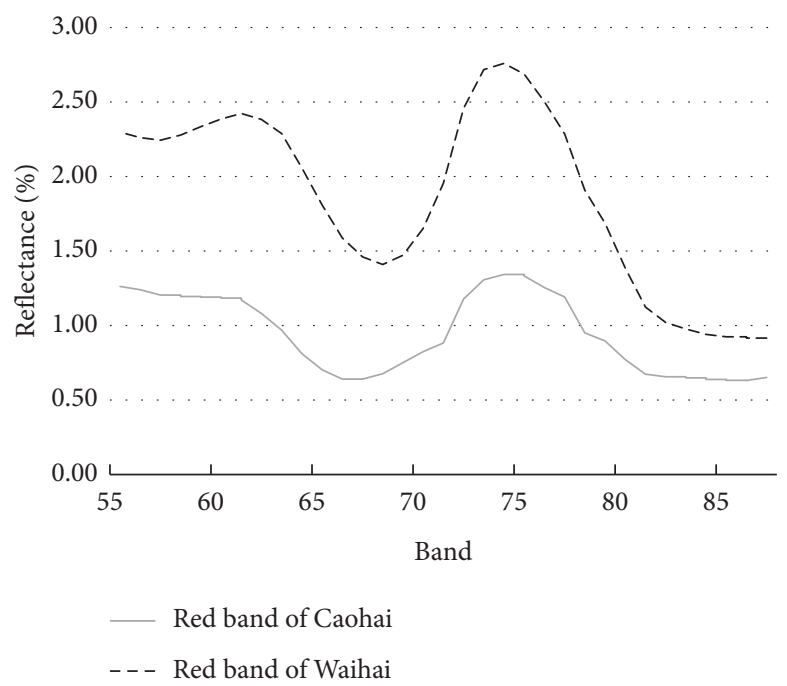

Figure 4: Spectral reflectance curves of Caohai and Waihai in the red band.

TABle 2: Characteristic bands of Caohai and Waihai in the red band.

\begin{tabular}{lccc}
\hline Area & Band & Reflectance value $(\%)$ & Band characteristics \\
\hline & B74 $(703 \mathrm{~nm})$ & 1.34 & Reflection peak, max \\
Caohai & B66 $(669 \mathrm{~nm})$ & 0.64 & Absorption valley \\
& B86 $(754 \mathrm{~nm})$ & 0.63 & Min \\
\hline
\end{tabular}


TABLE 2: Continued.

\begin{tabular}{|c|c|c|c|}
\hline Area & Band & Reflectance value (\%) & Band characteristics \\
\hline \multirow{4}{*}{ Waihai } & B74 $(703 \mathrm{~nm})$ & 2.76 & Reflection peak, $\max$ \\
\hline & B66 $(669 \mathrm{~nm})$ & 1.59 & Absorption valley \\
\hline & B86 $(754 \mathrm{~nm})$ & 0.92 & Min \\
\hline & & 1.86 & Mean \\
\hline
\end{tabular}

For the red band range, we found that the max reflectance of Caohai lies in B74 (value of 1.34\%), and the min reflectance lies in B86 (value of $0.63 \%$ ). The max reflectance of Waihai is in B74 (value of 2.76\%), and the min reflectance is in B86 (value of $0.92 \%$ ).

3.2. Characteristic Analysis of the Near-Infrared Band. Spectral reflection curves of the near-infrared band for Caohai and Waihai are shown in Figure 5. As we can see, both curves fluctuate sharply with the increase of band number. In the near-infrared band range, the curves' variation trends for the two water bodies are similar in general but with a significant difference in several bands. At the beginning and end of the curves, Waihai shows greater spectral reflectance than that of Caohai in B89-B119 and B263-B326, while in the middle range the situation is opposite, the reflectance of Caohai is greater than that of the Waihai in B120-B191 and B201-B241. The max reflectance difference is $1.04 \%$ in $\mathrm{B} 151$ and the $\mathrm{min}$ is in B117. The detailed information is shown in Table 3.

For the near-infrared band range, we found (Figure 5) that the max reflectance of Caohai is $1.84 \%$ in B151 and the min reflectance is $0.11 \%$ in $\mathrm{B} 285$. The max and $\min$ reflectance of Waihai lies in B99 (value of 1.24\%) and B166 (value of $0.08 \%$ ), respectively.

\subsection{Optimal NDVI Based on Hyperspectral Characteristic} Bands Recognition. In this section, the NDVI value is determined by combining the hyperspectral characteristic bands of the red and near-infrared bands. Tables 4 and 5 show the NDVI values of Caohai and Waihai, respectively, which were calculated by obtaining the corresponding reflectance values of the characteristic band in the red and near-infrared bands.

From Table 4, we found that the minimum value of NDVI $\left(\mathrm{NDVI}_{\min }\right)$ of Caohai is -0.84 when the reflectance of the red band is max and that of the near-infrared band is min. On the contrary, the maximum value of NDVI $\left(\mathrm{NDVI}_{\max }\right)$ is 0.49 when the reflectance of the red band is min and that of the near-infrared band is max. According to the conventional NDVI construction method, if the mean reflectance of red and near-infrared bands was selected, the NDVI value was -0.35 , which is close to the median of NDVI and not suitable for identifying aquatic plants.

From Table 5, we found that the $\mathrm{NDVI}_{\min }$ of Waihai is -0.95 when the reflectance of the red band is max and that of the near-infrared band is min. On the contrary, the $\mathrm{NDVI}_{\max }$ is 0.15 when the reflectance of the red band is min and that of the near-infrared band is max. Based on the conventional NDVI construction method, if the mean reflectance of red and near-infrared bands were selected, the NDVI value was -0.63 , which is also close to the median of NDVI.

Compared with the average reflectance based on red and near-infrared bands, the NDVI value calculated by the reflectance of characteristic bands is sharper and larger. After processing NDVI by maximum value composite, the influence of the atmosphere and solar altitude angle can be effectively reduced; the temporal and spatial variation of NDVI were analyzed $[29,30]$. Generally, when the NDVI value reaches the max, the spectral response effect is the best, which is more conducive to the identification of aquatic plants. In the presence of a water medium, the maximum NDVI can also have a better response to aquatic plants. Therefore, this study determines the optimal NDVI scheme based on the latter, which is different from the conventional NDVI calculation by using single or several bands. The approach avoids the influence of red edge displacement on the calculation results and provides a new calculation way of vegetation index [27].

By combining Tables $2-5$, the optimal NDVI value of Caohai is the value calculated by B86 and B151. Similarly, in Waihai, when the reflectance of the red band is the min (B86) and the near-infrared band (B99) reaches the max, it is the optimal NDVI value.

3.4. Spatial Differentiation of NDVI and Aquatic Plants (Water Quality) in Dianchi. It is well known that the NDVI value ranges from -1 to 1 . When the value is negative, it implies that the ground is covered with clouds, water, snow, etc. When the value is 0 , it reveals that there are rocks or bare soil, etc., and the reflectance of the near-infrared band is approximately equal to that of the red band. When the NDVI value is positive, it indicates the distribution of plants and an increase in NDVI value indicates an increase in plants [31]. When the NDVI value is 1 , it indicates that plants are in a good growth state and have a high coverage density. Based on this principle, the NDVI threshold dividing standard in the study area is obtained (Table 6).

Therefore, the calculated $\mathrm{NDVI}_{\max }$ is combined with Table 6 to reveal the spatial distribution of aquatic plants in Caohai and Waihai, the spatial differentiation of water quality in Caohai and Waihai was presented (Figure 6).

As can be seen in Figure 6(a), Caohai is dominated by sparse aquatic plants, while areas with no aquatic plants are mainly distributed in the northern Caohai, areas of dense aquatic plants are discretely distributed in the lakeshore zone. According to the statistics in Table 7, areas with NDVI value $[0,1)$ in Caohai account for about $90.425 \%$ of the total area, which is the largest proportion. The second proportion 


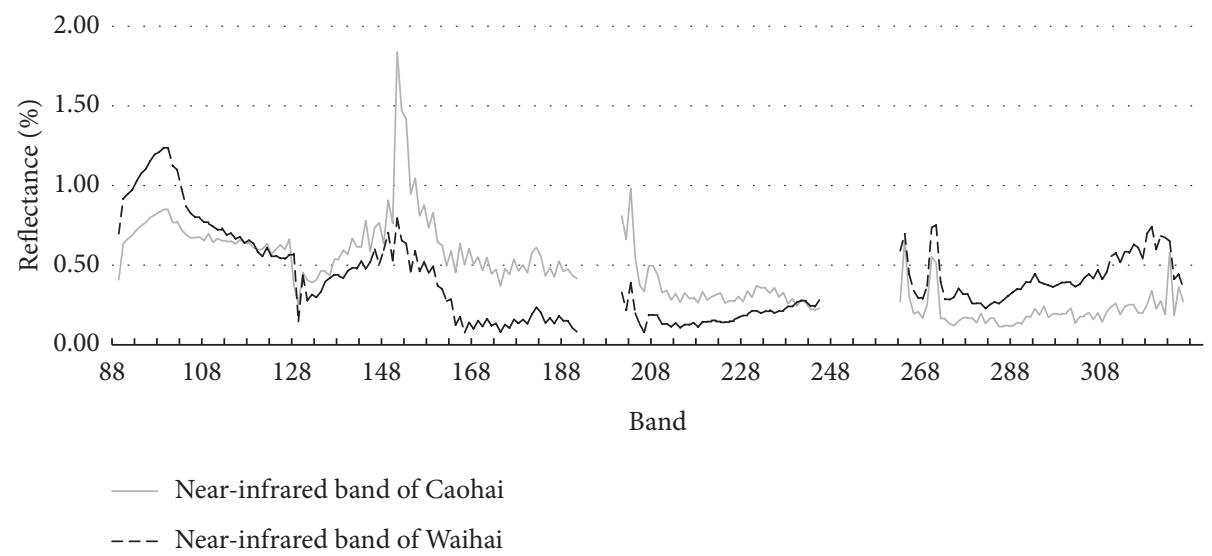

FIgURE 5: Spectral reflectance curves of Caohai and Waihai in the near-infrared band.

TABLE 3: Characteristic bands of Caohai and Waihai in the near-infrared band.

\begin{tabular}{|c|c|c|c|}
\hline Area & Band & Reflectance value (\%) & Band characteristics \\
\hline \multirow{11}{*}{ Caohai } & B99 $(810 \mathrm{~nm})$ & 0.85 & Reflection peak 1 \\
\hline & B151 (1005 nm) & 1.84 & Reflection peak 2 , max \\
\hline & B203 (1444 nm) & 0.98 & Reflection peak 3 \\
\hline & B264 (1957 nm) & 0.66 & Reflection peak 4 \\
\hline & B271 (2016 nm) & 0.52 & Reflection peak 5 \\
\hline & $\mathrm{B} 129(938 \mathrm{~nm})$ & 0.25 & Absorption valley 1 \\
\hline & B166 (1131 nm) & 0.50 & Absorption valley 2 \\
\hline & B206 (1469 nm) & 0.34 & Absorption valley 3 \\
\hline & B268 $(1991 \mathrm{~nm})$ & 0.17 & Absorption valley 4 \\
\hline & $\mathrm{B} 285(2134 \mathrm{~nm})$ & 0.11 & Absorption valley 5 , min \\
\hline & & 0.45 & Mean \\
\hline \multirow{11}{*}{ Waihai } & B99 $(810 \mathrm{~nm})$ & 1.24 & Reflection peak $1, \max$ \\
\hline & B151 (1005 nm) & 0.79 & Reflection peak 2 \\
\hline & B203 (1444 nm) & 0.39 & Reflection peak 3 \\
\hline & B264 $(1957 \mathrm{~nm})$ & 0.70 & Reflection peak 4 \\
\hline & $\mathrm{B} 271(2016 \mathrm{~nm})$ & 0.75 & Reflection peak 5 \\
\hline & B129 (938 nm) & 0.15 & Absorption valley 1 \\
\hline & $\mathrm{B} 166(1131 \mathrm{~nm})$ & 0.08 & Absorption valley $2, \mathrm{~min}$ \\
\hline & B206 $(1469 \mathrm{~nm})$ & 0.08 & Absorption valley 3 \\
\hline & B268 (1991 nm) & 0.29 & Absorption valley 4 \\
\hline & B285 $(2134 \mathrm{~nm})$ & 0.26 & Absorption valley 5 \\
\hline & & 0.42 & Mean \\
\hline
\end{tabular}

TABLE 4: NDVI values of characteristic bands in Caohai.

\begin{tabular}{lccccc}
\hline \multirow{2}{*}{$\begin{array}{l}\text { Near-infrared } \\
\text { band }\end{array}$} & & B66 & B74 & B86 & Mean \\
& & $0.64 \%$ & $1.34 \%$ & $0.63 \%$ & $0.95 \%$ \\
\hline B99 & $0.85 \%$ & 0.14 & -0.22 & 0.15 & -0.05 \\
B129 & $0.25 \%$ & -0.43 & -0.68 & -0.43 & -0.58 \\
B151 & $1.84 \%$ & 0.48 & 0.16 & 0.49 & 0.32 \\
B166 & $0.50 \%$ & -0.12 & -0.45 & -0.11 & -0.30 \\
B203 & $0.98 \%$ & 0.21 & -0.15 & 0.22 & 0.02 \\
B206 & $0.34 \%$ & -0.31 & -0.60 & -0.31 & -0.47 \\
B264 & $0.66 \%$ & 0.02 & -0.34 & 0.02 & -0.18 \\
B268 & $0.17 \%$ & -0.58 & -0.78 & -0.58 & -0.70 \\
B271 & $0.52 \%$ & -0.11 & -0.44 & -0.10 & -0.29 \\
B285 & $0.11 \%$ & -0.70 & -0.84 & -0.69 & -0.78 \\
Mean & $0.45 \%$ & -0.17 & -0.50 & -0.17 & -0.35 \\
\hline
\end{tabular}

TABLE 5: NDVI values of characteristic bands in Waihai.

\begin{tabular}{lccccc}
\hline \multirow{2}{*}{$\begin{array}{l}\text { Near-infrared } \\
\text { band }\end{array}$} & & B66 & B74 & B86 & Mean \\
& & $1.59 \%$ & $2.76 \%$ & $0.92 \%$ & $1.86 \%$ \\
\hline B99 & $1.24 \%$ & -0.13 & -0.38 & 0.15 & -0.20 \\
B129 & $0.15 \%$ & -0.83 & -0.90 & -0.73 & -0.85 \\
B151 & $0.79 \%$ & -0.33 & -0.55 & -0.07 & -0.40 \\
B166 & $0.08 \%$ & -0.91 & -0.95 & -0.85 & -0.92 \\
B203 & $0.39 \%$ & -0.61 & -0.75 & -0.40 & -0.65 \\
B206 & $0.08 \%$ & -0.91 & -0.94 & -0.84 & -0.92 \\
B264 & $0.70 \%$ & -0.39 & -0.60 & -0.14 & -0.45 \\
B268 & $0.29 \%$ & -0.69 & -0.81 & -0.52 & -0.73 \\
B271 & $0.75 \%$ & -0.36 & -0.57 & -0.10 & -0.42 \\
B285 & $0.26 \%$ & -0.72 & -0.83 & -0.56 & -0.76 \\
Mean & $0.42 \%$ & -0.58 & -0.74 & -0.37 & -0.63 \\
\hline
\end{tabular}


TABLE 6: NDVI threshold division standard.

\begin{tabular}{lccc}
\hline NDVI value & $-1 \leq$ NDVI $<0$ & $0 \leq$ NDVI $<1$ & NDVI $=1$ \\
\hline Degree & No aquatic plants & Sparse aquatic plants & Dense aquatic plant \\
\hline
\end{tabular}

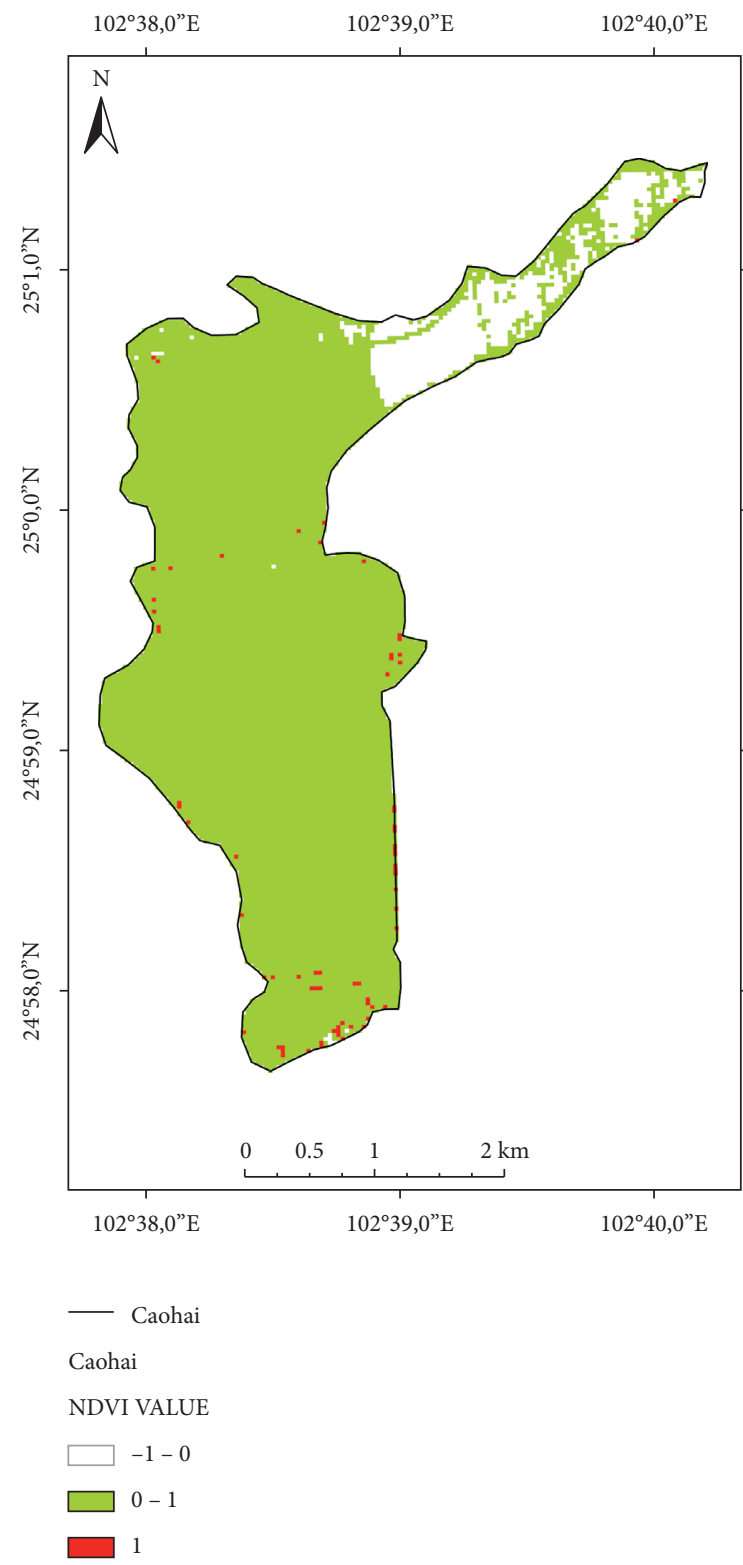

(a)

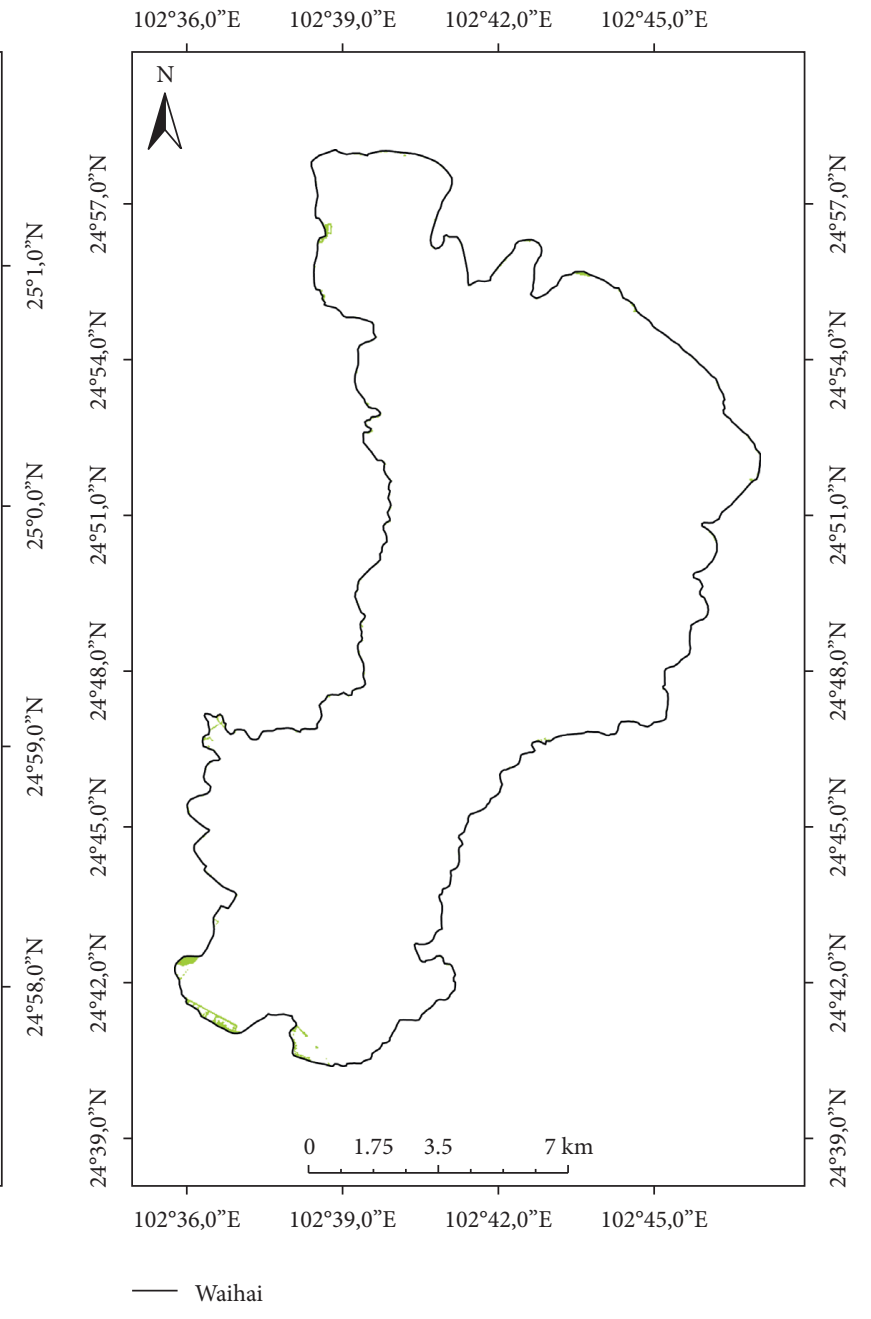

Waihai

NDVI VALUE

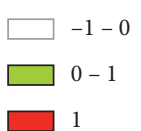

on NDVI value.

TABLE 7: The proportion of NDVI threshold in the study area.

\begin{tabular}{lccc}
\hline NDVI value & $-1 \leq \mathrm{NDVI}<0(\%)$ & $0 \leq \mathrm{NDVI}<1(\%)$ & $\mathrm{NDVI}=1(\%)$ \\
\hline Caohai & 8.922 & 90.425 & 0.653 \\
Waihai & 99.277 & 0.722 & 0.001 \\
\hline
\end{tabular}


is the area with NDVI value $[-1,0)$, taking up about $8.922 \%$, about $0.653 \%$ of the total area suffers extreme water quality problems (with NDVI value of 1). Only the water quality in the northern Caohai is under good condition, with no aquatic plants. For most regions, Caohai is characterized by poor water quality situation.

As can be seen in Figure 6(b), Waihai is mainly characterized by no aquatic plants. The sparse aquatic plants' areas are primarily located in the southern and northern Waihai, as well as a dispersed distribution in the lakeshore zone, while the dense aquatic plants' areas are almost not found. According to the statistics in Table 7, for Waihai, areas with NDVI value $[-1,0)$ accounts for about $99.277 \%$ of the total area, which is the largest proportion. The second proportion is areas with NDVI value $[0,1)$, contributing about $0.722 \%$ of the total area. Areas with an NDVI value of 1 account for only about $0.001 \%$. For Waihai, poor water quality conditions mainly occurred in the north and south, and the water quality in the rest areas is acceptable. We also noticed that water quality from the lakeside zone to the central lake showed a conspicuous descending trend.

By comparing Figures 6(a) and 6(b), significant regional differences of NDVI were found for both water bodies. Meanwhile, under the same threshold division standard, the proportion of sparse aquatic plants in Caohai is much larger than that in Waihai, which is $90.425 \%$ and $0.722 \%$, respectively. Moreover, the proportion of dense aquatic plants in Caohai is also larger than that in Waihai, which is $8.922 \%$ and $0.001 \%$, respectively. Therefore, Caohai is suffering from more water environmental problems than Waihai; especially in southern Caohai, the situation is far worse than that of northern Waihai.

3.5. Comparison with Local Experiments. A wide variety of approaches have been employed by many local scholars to study the spatial differentiation in Dianchi Lake, such as $\mathrm{He}$ et al. [12]. Based on the 16-day synthetic $250 \mathrm{~m} \times 250 \mathrm{~m}$ resolution NDVI data product of MODIS image from 2000 to 2017, the spatiotemporal distribution of NDVI in Dianchi Lake was analyzed in detail. The distribution area and spatial variation characteristics of different levels of cyanobacterial blooms were discussed. The results showed that annual NDVI in the Dianchi area showed a decreasing trend from 2000 to 2017. The bloom coverage of cyanobacteria decreased, and the eutrophication bias was alleviated. And the area without water bloom accounted for the largest proportion in December for many years. The cyanobacteria bloom was heavier in the north region in Dianchi Lake than that of the south region. The relatively serious areas of water bloom were concentrated in the North of Caohai, Broken Bridge, and Hui Bay.

Furthermore, to investigate the relationship of algal community dynamics with nitrogen and phosphorus concentrations in Dianchi Lake, Hou et al. [32] monitored the planktonic algae biomass and the concentrations of nitrogen and phosphorus monthly from May 2013 to April 2015. The spatial-temporal heterogeneity of nitrogen and phosphorus concentrations in Dianchi Lake was then analyzed. According to the geographical location of Dianchi Lake, 10 sampling points were established in Caohai and Waihai (Figure 7). There are 2 sampling points in Caohai, including the center of Caohai and Broken Bridge, located in the central and southern parts, respectively. And there are 8 sampling points in Waihai. The northern part includes Hui Bay and Luojiaying. The central part includes the West of Guanyin Mountain, Baiyukou, East of Guanyin Mountain. The southern part includes the West of Haikou and South of Dianchi. The water samples were taken back to the laboratory every January, and the algae in water samples were detected by Phyto-PAM. The contents of total nitrogen and total phosphorus were detected by a hash water quality analyzer (DR5000). The results showed that in December each year, the nitrogen and phosphorus in Caohai were higher than those in Waihai, indicating that the eutrophication level in Caohai was higher than that in Waihai. The biomass of green algae in Caohai was higher than that of cyanobacteria, and the biomass of green algae in Caohai was much higher than that in Waihai. To sum up, it was proved that the water quality of Caohai is worse than that of Waihai.

There are still many local studies [33] similar to the above-mentioned ones with different perspectives. The results of this study are also consistent with those local experiments, so the study methods and results of this study are feasible to some degree for rapid water environment assessment.

\section{Discussions}

Dianchi Lake is the biggest plateau lake in Yunnan province and the governance of which has attracted much attention. In recent years, with the unremitting efforts of the government and the community, the water environment condition of Dianchi Lake has been steadily improved. According to $\mathrm{He}$ et al. [12], areas with no aquatic plants accounted for $69.34 \%$ of the total area of Dianchi Lake in the winter of 2000. The estimates of this study show that the same ratio of Dianchi Lake in the winter of 2019 is $96.30 \%$. It can also be found that the water quality of Dianchi was significantly improved by referring to relevant information. From 2015 to 2019, the water quality of Dianchi changed from severe pollution to mild pollution, which achieved a leap-forward improvement from superclass V to IV. In 2019, the concentrations of chemical oxygen demand, ammonia nitrogen, total phosphorus, and total nitrogen in Dianchi were $28 \mathrm{mg} / \mathrm{L}, 0.14 \mathrm{mg} /$ $\mathrm{L}, 0.07 \mathrm{mg} / \mathrm{L}$, and $1.26 \mathrm{mg} / \mathrm{L}$, respectively, decreasing by $40 \%$, $65 \%, 41 \%$, and $45 \%$ compared with 2015 , respectively [34]. This shows that the government's approach to scientific, systematic, intensive, and law-based governance over the past few years has been effective. To realize a long-term cooperation mechanism with universities and scientifically solve the technical difficulties of lake governance, pay attention to the overall production and lifestyle optimization in the Dianchi basin. Enact relevant laws and regulations to form a mechanism for rule of law. Although some achievements have been made, there is still a long way to go for the governance of Dianchi Lake in the future. 


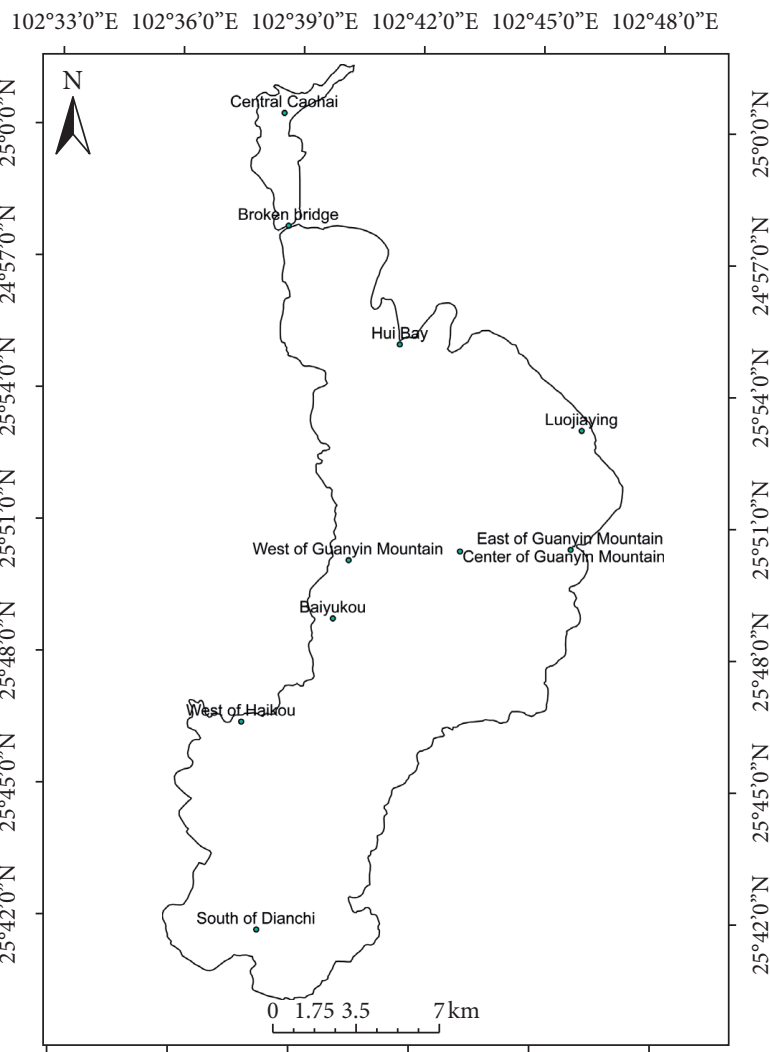

$102^{\circ} 33^{\prime} 0^{\prime \prime} \mathrm{E} 102^{\circ} 36^{\prime} 0^{\prime \prime} \mathrm{E} 102^{\circ} 39^{\prime} 0^{\prime \prime} \mathrm{E} 102^{\circ} 42^{\prime} 0^{\prime \prime} \mathrm{E} 102^{\circ} 45^{\prime} 0^{\prime \prime} \mathrm{E} 102^{\circ} 48^{\prime} 0^{\prime \prime} \mathrm{E}$

Figure 7: Location of sampling sites in Dianchi Lake.

To prove that the NDVI obtained from hyperspectral data is superior to multispectral data in water quality estimation. The multispectral data of Landsat8 were taken as an example to verify the results through concrete experiments. In this paper, Landsat8 multispectral remote sensing images of Dianchi Basin with the closest time interval were obtained. This image was taken on November 15, 2019; data ID is LC81290432019319LGN00. By applying Band $4(655 \mathrm{~nm})$ and Band $5(865 \mathrm{~nm})$ of Landsat8 to calculate the NDVI of Caohai and Waihai, NDVI thresholds are divided according to the standard in Table 6. The spatial distribution of water quality in Dianchi based on NDVI value as shown in Figure 8 is obtained. The NDVI calculated by Landsat 8 does not belong to the range of $[-1,0)$, and it is difficult to reflect the spatial distribution characteristics of aquatic plants in Dianchi in Figure 8. It can be found that compared with multispectral data, hyperspectral data have a better effect on water quality estimation.

This study gains a good command of the theoretical basis for constructing optimal NDVI using hyperspectral characteristic bands, but there are still some shortcomings. NDVI is the most commonly applied vegetation index to analyze the regional-scale distribution of aquatic plants. However, when we calculate the NDVI value of aquatic plants, the results are not only affected by the atmospheric factors but also by the water medium. Information about aquatic plants in deep water is difficult to be obtained, so the NDVI value will be underestimated to some degree. To

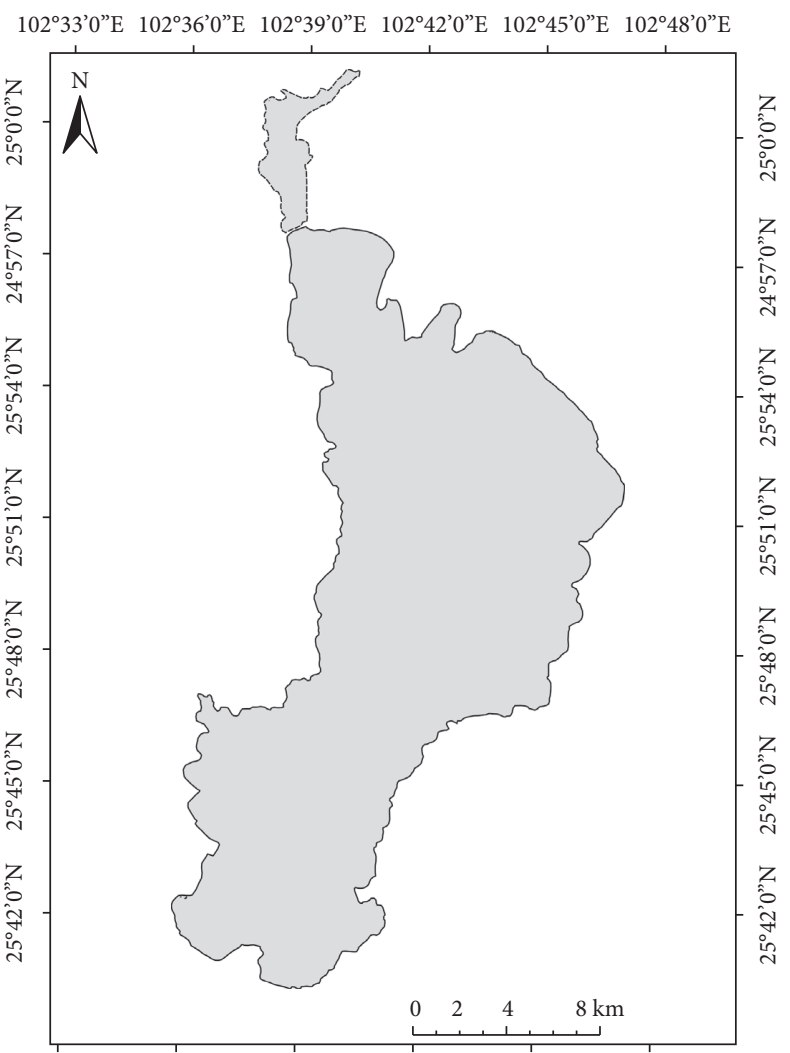

$102^{\circ} 33^{\prime} 0^{\prime \prime} \mathrm{E} 102^{\circ} 36^{\prime} 0^{\prime \prime} \mathrm{E} 102^{\circ} 39^{\prime} 0^{\prime \prime} \mathrm{E} 102^{\circ} 42^{\prime} 0$ " E $102^{\circ} 45^{\prime} 0^{\prime \prime} \mathrm{E} 102^{\circ} 48^{\prime} 0^{\prime \prime} \mathrm{E}$

\begin{tabular}{ll}
--- Caohai & Waihai \\
Caohai & Waihai \\
VALUE & VALUE \\
$\square 0-1$ & $0-1$ \\
\hline 1 & 1
\end{tabular}

FIGURE 8: Spatial distribution of water quality in Dianchi based on NDVI value.

identify aquatic plants more accurately and quickly, the precision can be improved by refining research methods and enriching data sources in the future. In addition, we will pay more attention to multiperiod change detection. Since GF-5 is a satellite launched in recent years, historical data are limited. With the accumulation of time-series images, the research methods are continuously optimized in combination with hyperspectral data. Comprehensive application of multisource remote sensing technology to establish a more perfect water quality monitoring program is also considered. By supplementing these contents, this work can realize the prediction of water pollution in inland lakes and promote the scientific management of plateau water resources based on remote sensing technology.

\section{Conclusions}

Through the experimental study in this paper, the following conclusions are drawn:

(1) NDVI plays an important role in monitoring aquatic plants, while hyperspectral data has a high spectral 
resolution. How to select the bands to make the effective construction of NDVI has become a challenge for hyperspectral images. This problem was solved through a series of experiments and research in this study. Under the principle that when NDVI reaches the max, the spectral response effect is the best and easy to identify aquatic plants, so the optimal NDVI can be constructed using characteristic band reflectance. When the reflectance of the red band is the min and the near-infrared band is the max, it is the optimal NDVI. Specifically, the optimal NDVI value of Caohai is calculated by B86 and B151, while the optimal NDVI value of Waihai is determined by B86 and B99.

(2) For Caohai, only the water quality in northern parts is acceptable and no aquatic plants are found in this region, but for most regions, the aquatic plants' situation and the quality of the lake water environment are not optimistic and need to be taken seriously. The water quality problems in Waihai are mainly concentrated in the north and south. Generally, there is a descending trend in water quality from the lakeside zone to the central lake.

(3) Under the same threshold division standard, both the proportions of sparse aquatic plants and dense aquatic plants in Caohai are much larger than those of Waihai. Caohai is suffering from more water environmental problems than Waihai, and the water quality in southern Caohai is far worse than that of northern Waihai.

(4) By comparing the research results to local studies in the winter of 2000, it is found that a series of measures taken by the government to protect and control Dianchi Lake during these years are extremely effective. Although some achievements have been made, there is still a long way to go for the governance of Dianchi Lake in the future.

\section{Data Availability}

The GF-5 hyperspectral data that support the findings of this study are conditionally available in the Yunnan Applied Research Center for Earth Observation Data. The data are not publicly available because they contain information that could compromise the privacy of Yunnan Applied Research Center for Earth Observation Data.

\section{Conflicts of Interest}

The authors declare that there are no conflicts of interest regarding the publication of this article.

\section{Authors' Contributions}

$\mathrm{Hu}$ Lin wrote the manuscript and Gan Shu designed the framework of the research; Yuan Xiping and Chen Guokun have given many suggestions for improving and modifying this paper; and Li Yan and Gao Sha contributed to data processing and analysis. All the authors were involved in result analysis and discussion.

\section{Acknowledgments}

Thanks are due for the field investigation work done by many students from the "Yunnan Province University Engineering Research Center of Spatial Information Surveying and Mapping Technology Application in Highland Mountain Area" and "Yunnan Applied Research Center for Earth Observation Data." This work was supported by the National Natural Science Foundation of China (NSFC) project, "Multi-Scale Remote Sensing Detection and Analysis of Debris Flows in Dongchuan Xiaojiang" (Grant no. 41861054).

\section{References}

[1] L. Yang, X. Yang, L. Ren, X. Qian, and L. Xiao, "Mechanism and control strategy of cyanobacterial bloom in Lake Taihu," Journal of Lake Sciences, vol. 31, no. 1, pp. 18-27, 2019, in Chinese.

[2] P. Dolezelova, S. Macova, and V. Plhalova, "The acute toxicity of clove oil to fish Danio rerio and Poecilia reticulata," Acta Veterinaria Brno, vol. 80, no. 3, pp. 305-308, 2011.

[3] W. Liu, N. Yang, S. Zhang et al., "Relationship between phytoplankton community changes and environmental factors during the interchange of autumn and winter in a lowsalinity lagoon," Chinese Journal of Ecology, vol. 39, no. 10, pp. 3342-3349, 2020, in Chinese.

[4] J. Wang, L. He, C. Yang et al., "Comparison of algal bloom related meteorological and water quality factors and algal bloom conditions among Lakes Taihu, Chaohu and Dianchi (1981-2015)," Journal of Lake Sciences, vol. 30, no. 4, pp. 897-906, 2018, in Chinese.

[5] L. Hu, S. Gan, X. Yuan et al., "Difference analyses on hyperspectral characteristics of water bodies with different spatial distribution in Dianchi Lake," Journal og Yunnan University (Natural Science Edition), vol. 42, no. 4, pp. 695700, 2020, in Chinese.

[6] C. B. Obida, G. A. Blackburn, J. D. Whyatt, and K. T. Semple, "Counting the cost of the Niger Delta's largest oil spills: satellite remote sensing reveals extensive environmental damage with $>1$ million people in the impact zone," The Science of the Total Environment, vol. 775, 2021.

[7] H. Lyu, Z. Yang, L. Shi et al., "A novel algorithm to estimate phytoplankton carbon concentration in inland lakes using sentinel-3 OLCI images," IEEE Transactions on Geoscience and Remote Sensing, vol. 58, no. 9, pp. 6512-6523, 2020.

[8] C. Giardino, V. E. Brando, P. Gege et al., "Imaging spectrometry of inland and coastal waters: state of the art, achievements and perspectives," Surveys in Geophysics, vol. 40, no. 3, pp. 401-429, 2019.

[9] K. Song, C. Fang, P.-A. Jacinthe et al., "Climatic versus anthropogenic controls of decadal trends (1983-2017) in algal blooms in lakes and reservoirs across China," Environmental Science \& Technology, vol. 55, no. 5, pp. 2929-2938, 2021.

[10] X. Pi, L. Feng, W. Li, D. Zhao, X. Kuang, and J. Li, "Water clarity changes in 64 large alpine lakes on the Tibetan Plateau and the potential responses to lake expansion," ISPRS Journal of Photogrammetry and Remote Sensing, vol. 170, pp. 192-204, 2020. 
[11] L. Hu, S. Gan, X. Yuan, R. Li, and R. Bi, "Study on the spatial distribution characteristics of yanobacteria bloom in Dianchi Lake based on GF-5," Laser \& Infrared, vol. 51, no. 2, pp. 237-243, 2021, in Chinese.

[12] Y. He, Q. Xiong, X. Luo, T. Li, and L. Yu, "Study on spatiotemporal changes of water bloom in Dianchi Lake based on NDVI," Ecology and Environmental Sciences, vol. 28, no. 3, pp. 555-563, 2019.

[13] S. Oiry and L. Barille, "Using sentinel-2 satellite imagery to develop microphytobenthos-based water quality indices in estuaries," Ecological Indicators, vol. 121, 2021.

[14] K. L. Wilson, M. C. Wong, and E. Devred, "Branching algorithm to identify bottom habitat in the optically complex coastal waters of atlantic Canada using sentinel-2 satellite imagery," Frontiers in environmental science, vol. 8, 2020.

[15] K. Shi, Y. Zhang, B. Qin, and B. Zhou, "Remote sensing of cyanobacterial blooms in inland waters: present knowledge and future challenges," Science Bulletin, vol. 64, no. 20, pp. 1540-1556, 2019.

[16] N. Chen, S. Wang, X. Zhang, and S. Yang, "A risk assessment method for remote sensing of cyanobacterial blooms in inland waters," The Science of the Total Environment, vol. 740140012 pages, 2020.

[17] H. Yue, Y. Li, J. Qian, and Y. Liu, "A new accuracy evaluation method for water body extraction," International Journal of Remote Sensing, vol. 41, no. 19, pp. 7311-7342, 2020.

[18] D. Zhang, X. Yin, B. She et al., "Using multi-source satellite imagery data to monitor cyanobacterial blooms of Chaohu Lake," Infrared and Laser Engineering, vol. 48, no. 7, pp. 303-314, 2019.

[19] H. Zhang, K. Gu, and S. Zhang, "Extracting temporal and spatial distribution features of Lake Taihu from MODIS-EVI data by empirical orthogonal function analysis," Chinese Journal of Ecology, vol. 37, no. 12, pp. 3802-3808, 2018, in Chinese.

[20] Y. Lin, C. Pan, Y. Chen, and W. Ren, "Recognition of cyanobacteria bloom based on spectral analysis of remote sensing imagery," Journal of Tongji University, vol. 39, no. 8, pp. 1247-1252, 2011.

[21] J.-H. Wang, C. Yang, L.-Q.-S. He et al., "Meteorological factors and water quality changes of Plateau Lake Dianchi in China (1990-2015) and their joint influences on cyanobacterial blooms," The Science of the Total Environment, vol. 665, pp. 406-418, 2019.

[22] Q. Chen, Z. Ni, S. Wang, Y. Guo, and S. Liu, "Climate change and human activities reduced the burial efficiency of nitrogen and phosphorus in sediment from Dianchi Lake, China," Journal of Cleaner Production, vol. 274, Article ID 122839, 2020.

[23] K. Yan, Z. Yuan, S. Goldberg et al., "Phosphorus mitigation remains critical in water protection: a review and metaanalysis from one of China's most eutrophicated lakes," The Science of the Total Environment, vol. 689, pp. 1336-1347, 2019.

[24] L. Wan, Y. Lin, H. Zhang, F. Wang, M. Liu, and H. Lin, “GF-5 hyperspectral data for species mapping of mangrove in Mai Po, Hong Kong," Remote Sensing, vol. 12, no. 4, 656 pages, 2020.

[25] B. Li, B. Zhou, X. He, and H. Liu, "Status and prospects of target classification methods based on hyperspectral images," Laser \& Infrared, vol. 50, no. 3, pp. 259-265, 2020.

[26] K. Ren, W. Sun, X. Meng, G. Yang, and Q. Du, "Fusing China GF-5 hyperspectral data with GF-1, GF-2 and sentinel-2A multispectral data: which methods should be used?" Remote Sensing, vol. 12, no. 5, 882 pages, 2020.

[27] N. Hashimoto, Y. Saito, M. Maki, and K. Homma, "Simulation of reflectance and vegetation indices for unmanned aerial vehicle (UAV) monitoring of paddy fields," Remote Sensing, vol. 11, no. 18, 2019.

[28] A. Cogato, F. Meggio, C. Collins, and F. Marinello, "Mediumresolution multispectral data from sentinel-2 to assess the damage and the recovery time of late frost on vineyards," Remote Sensing, vol. 12, no. 11, 2020.

[29] Y. Li, C. Zhang, W. Luo, and W. Gao, "Summer maize phenology monitoring based on normalized difference vegetation index reconstructed with improved maximum value composite," Transactions of the Chinese Society of Agricultural Engineering, vol. 35, no. 14, pp. 159-165, 2019.

[30] Y. Xi, Y. Xu, and X. Liu, "Spatiotemporal changes of different vegetation coverage in jiangsu province in the period from 2000 to 2013," Research of Soil and Water Conservation, vol. 23, no. 1, pp. 86-91, 2016.

[31] Y. Jiang, L. Jiao, and B. Zhang, "Scale effect of the spatial correlation between urban land surface temperature and NDVI," Progress in Geography, vol. 37, no. 10, pp. 1362-1370, 2018, in Chinese.

[32] X. Hou, C. Yuan, X. Li, Y. Ren, Y. Luo, and D. Wang, "Effect of nitrogen and phosphorus concentrations on the planktonic algae dynamics in Dianchi Lake," Journal of Hydroecology, vol. 39, no. 1, pp. 16-22, 2018, in Chinese.

[33] Y. Youjin, F. X. Jing, F. Xiangjing et al., "Spatial and temporal distribution patterns of loadings of different phosphorous forms in Lake Dianchi," Journal of Lake Sciences, vol. 29, no. 1, pp. 59-68, 2017.

[34] http://huanbao.newssc.org/system/20200902/002991557.htm. 